\title{
Comparative parasitological examination on sympatric equids in the Great Gobi "B" Strictly Protected Area, Mongolia
}

\author{
Johanna Painer • Petra Kaczensky • \\ Oyunsaikhan Ganbaatar • Klaus Huber • Chris Walzer
}

Received: 12 January 2010 /Revised: 8 June 2010 / Accepted: 11 June 2010 /Published online: 17 July 2010

(C) The Author(s) 2010. This article is published with open access at Springerlink.com

\begin{abstract}
The Przewalski's horse (Equus caballus przewalskii) became extinct in the wild during the 1960s. Based on a successful captive breeding program, Przewalski's horses were reintroduced to the Great Gobi Part "B" strictly protected area (SPA) in SW Mongolia in the late 1990s. The Asiatic wild ass (Equus hemionus hemionus), Przewalski's horse, and sometimes domestic horses live sympatricly in the Gobi B SPA. Previously published data demonstrates that, as a result of their different requirements and utilization of the park's resources, their home-range size and social structure differ. Parasitological examinations in the three equid species show how the factors "home range, social structure, and resource selection" significantly impact parasitic burden. Asiatic wild asses are potentially exposed to a higher risk of parasite re-infection due to their temporal aggregation in very large groups. This
\end{abstract}

Communicated by C. Gortázar

J. Painer $(\bowtie) \cdot$ P. Kaczensky $\cdot$ K. Huber $\cdot$ C. Walzer

Research Institute of Wildlife Ecology,

University of Veterinary Medicine,

Vienna, Austria

e-mail: johanna.painer@hotmail.com

P. Kaczensky $\cdot$ O. Ganbaatar $\cdot$ C. Walzer

International Takhi Group,

CH-8135 Sihlwald, Schweiz

O. Ganbaatar

Department of Zoology, Faculty of Biology,

National University of Mongolia,

Ulaanbaatar, Mongolia

O. Ganbaatar

Gobi B Strictly Protected Area Administration,

Gobi, Mongolia study demonstrates a highly significant greater parasite load in the Asiatic wild ass for the majority of parasites evaluated (Dictyocaulus arnfieldi, Trichostrongylus axei, Strongyloides westeri, Parascaris equorum) compared to Przewalski's horses and domestic horses in the same habitat. Domestic horses had higher parasite loads for eggs of strongylids, eggs of anoplocephalidae, and Eimeria leuckarti. The potential risk of cross infection between sympatric living equids is high, as is the cross infection between ruminants and equids. Furthermore, this study reports for the first time the occurrence of lungworms in free-ranging Przewalski's horses. Whereas, Asiatic wild asses and Przewalski's horses seem to cope very well with the sometimes high parasite burden, Mongolian domestic horses manifested typical parasite burden symptoms.

Keywords Przewalski's horse · Asiatic wild ass · Parasites · Sympatric $\cdot$ Cross-infection $\cdot$ Home range

\section{Introduction}

The Great Gobi "B" strictly protected area (SPA) in SW Mongolia is one of the few places in the world where the habitats of different wild equids overlap, and the only area where the Asiatic wild ass (Equus hemionus hemionus, locally known as "Khulan", PALLAS 1775) and Przewalski's horse (Equus caballus przewalskii, locally known as "Takhi", Poliakov 1881) live sympatricly, and seasonally share pastures with domestic horses (Equus ferrus caballus, LINNAEUS 1758).

Przewalski's horses were once widespread over the central Asiatic steppes. It was discovered by the western world in the late nineteenth century and, until 1947, was 
captured and transported to zoological gardens. The last sightings of wild individuals were in the Dzungarian desert, in southwestern Mongolia. In the late 1960s, the Przewalski's horse was declared extinct in the wild (Boyd and Houpt 1994). The species was successfully bred ex-situ based on a reproductive founder population of only 13 individuals (Mohr and Volf 1971). First efforts to start a reintroduction program were undertaken in 1979, but it was only in 1992 that the first individuals were transported to the Takhin Tal reintroduction site $(45.53 .80 \mathrm{~N}, 93.65 .22 \mathrm{E})$. After the establishment of the International Takhi Group (ITG) in 1999, the project was extended in accordance with the International Union for the Conservation of Nature (IUCN) reintroduction guidelines (Walzer et al. 2004; IUCN/SSC 1998). Since the onset of the project, 89 individuals have been transported from 24 zoos (Kaczensky et al. 2005). In the first years of the project, Przewalski's horses were kept in adaptation enclosures, and only in 1997 the first harem group was released into the wild (Walzer et al. 2004). Today, some 145 free-ranging Przewalski's horses, in 10 harem groups and a varying number of bachelor groups, live in the protected area (ITG 2009, http://www.savethewildhorse.org).

The Asiatic wild ass population is estimated at 19,00020,000 individuals in Mongolia, with less than 5,000 individuals remaining outside Mongolia (Kaczensky et al. 2006). Approximately 2,000 Asiatic wild asses live in the Great Gobi "B" SPA (Kaczensky et al. 2008). The Asiatic wild ass has been under full protection in Mongolia since 1953, listed as vulnerable in the IUCN Red List since 2006, in Appendix I of CITES since 1973 and in Appendix II of the Convention on Migratory Species since 2002 (Kaczensky and Walzer 2008). The Asiatic wild ass was historically common on the steppes and deserts of the Middle East and central Asia. Today, the Asiatic wild ass exists only in 5\% of its former range (Kaczensky and Walzer 2008). The population size has decreased significantly due to wild asshuman conflicts, poaching, and habitat loss (Kaczensky et al. 2007; Kuehn et al. 2006). Based on historic records, the former distribution ranges of Przewalski's horse and Asiatic wild ass overlapped in the Dzungarian desert before the Przewalski's horse became extinct in the wild (Boyd and Houpt 1994).

The Mongolian domestic horse lives in a semi-feral fashion, moderately herded during the year and largely selecting pasture with few outside constraints.

Previously, very few parasitological investigations have been performed on these species, particularly not comparative studies. The goal of this study was to evaluate the parasite burden in the three equid species and explore possible linkages to home range size, social system structure, and resource selection. Furthermore, we compared the results of this study with a previous parasitological study performed in the Great Gobi "B" in 2001 and 2002 (Elias et al. 2002).

\section{Material and methods}

Study area

The Mongolian government in 1974 declared $9,000 \mathrm{~km}^{2}$ between the Altai range and the Chinese border in the southwestern part of Mongolia a protected area: the Great Gobi Part "B". This area was declared a "strictly protected area" (category 1a) by the IUCN in 1991. The climate is continental, with temperatures ranging from $+40^{\circ} \mathrm{C}$ in the short summer periods to $-40^{\circ} \mathrm{C}$ in the extended winter periods (Kaczensky et al. 2007). Average annual precipitation is $<100 \mathrm{~mm}$, with a peak in summer. Average snow cover lasts 97 days (Kaczensky et al. 2008). The area consists mainly of desert steppes and semi-deserts, and exhibits the dynamics of a non-equilibrium model of rangeland vegetation. Ungulate population fluctuations in the area are driven by the amount and timing of rainfall events (Fernandez-Gimenez and Allen-Diaz 1999).

\section{Parasitological examination}

Between July and August 2008, 113 fecal samples were collected in the Great Gobi "B" SPA. Forty samples were taken from Przewalski's horses, 31 from Asiatic wild asses, and 29 from Mongolian domestic horses. Thirteen samples were invalid due to procedural errors. None of the equids where treated with anti-parasitic agents during the past few years. To avoid contamination of feces with soil nematodes, only the inner pellets (inner and outer parts of the pellets) from a fresh fecal pile were used for the examinations. The fecal samples were collected in the morning, stored as cool as possible $\left(<20^{\circ} \mathrm{C}\right)$, and analyzed during the afternoon of the same day. For Przewalski's horses and domestic horses, age and sex differentiation was possible in most cases. For Asiatic wild ass, owing to the shyness and the absence of sexual dimorphism, it was not possible to determine age and sex. To avoid mistaking Asiatic wild ass feces with that of other equids, samples were only collected in areas where Przewalski's and domestic horses had not recently been sighted by rangers and other researchers. Additionally, wild ass fecal pellets differ significantly in shape and size from those of Przewalski's and domestic horses.

Each sample was examined with the combined sedimentation flotation method (CSFM, modified Stoll method using sugar concentrations of $1250 \mathrm{~g} / 11$ of aqua font), the sedimentation method (Benedek's method), and was tested for lungworms (Baerman method) (Schnieder et al. 2006). 
Based on morphology and size, parasite stages were differentiated under a microscope (Schnieder et al. 2006). We performed a semi-quantitative evaluation of egg, oocysts, and larval output under $100 \times$ magnification similar to the method described by Hoby et al. (2006). The sum of strongyles including Trichostrongylus axei per $10 \mathrm{~g}$, sum of egg or oocyst output for each parasite species per $10 \mathrm{~g}$, and sum of larval output per $20 \mathrm{~g}$ were recorded for each fecal sample. Additionally, we recorded which water point the group was using, in which area their home range was situated, and, if possible, group size, age, and sex.

\section{Visual observations}

To avoid disturbance of the herds, Przewalski's horses and domestic horse groups were observed from a distance of approximately 50-100 m. We used a Vector GIS-Binocular, which is able to measure the distance and the angle to the observed object via laser distance measurement (Leica Vector 1500), in combination with a global positioning satellite (GPS) fix from a hand-held unit (Garmin, GPS $60 \mathrm{Cx})$ to recover individual fecal samples. In contrast, Asiatic wild ass in the Gobi " $\mathrm{B}$ " are extremely shy and skittish, and could only be observed during the day from distances $>1 \mathrm{~km}$, or from a hide at a water point.

\section{Statistical analysis}

We used generalized linear models and analysis of variance (ANOVA) (Crawley 2007) to compare the different variables: individual egg count, oocyst count and lungworm larvae count, and strongyles, including $T$. axei with variables like home range size, resource selection type, social system type, sex, age, watering location, and group size. We used the statistical software R 2.8.1. (RDevelopment Core Team 2008). The level for statistical significance was set to $p \leq 0.05$.

\section{Results}

The following parasites were found in all three species (listed from highest to lowest burden): Dictyocaulus arnfieldi (COBBOLD 1879), T. axei (COBBOLD 1879), strongyles excluding T. axei (MÜLLER 1780), Strongyloides westeri (IHLE 1917), eggs of anoplocephalidae (GOEZE 1782), Parascaris equorum (GOEZE 1782), Eimeria leuckarti (FLESCH 1883), as well as occasional sightings of Gasterophilus spp. (DE GEER 1776) larvae in the feces (Table 1).

Age was a significant factor when comparing the egg count for each parasite species (ANOVA, DF=4, $p=<0.007$ ) for Przewalski's horses and domestic horses. In younger individuals, the load of $S$. westeri was significantly higher (glm, DF=62, $p=<0.004$, Estimates $=-0.93$ ). P. equorum also tended to be present in higher numbers in younger individuals, though this was not significant. E. leuckarti showed no significant difference of load in respect to age. The other parasite species (D. arnfieldi, T. axei, strongyles excluding $T$. axei, eggs of anoplocephalidae) produced a slightly higher or equal burden in adult equids. Yearlings showed a non-significant higher variability in parasite species present with similar quantitative levels as adult horses. There was no significant relationship between sex and parasite levels.

In the study area, the prevalence of each parasite in Przewalski's horse was $65.0 \%$ for $D$. arnfieldi, $67.5 \%$ for T. axei, $32.5 \%$ for strongyles excluding $T$. axei, $12.5 \%$ for $S$. westeri, $2.5 \%$ for $P$. equorum and eggs of anoplocephalidae, and $0 \%$ for E. leuckarti. In Asiatic wild ass, the prevalence was $64.5 \%$ for $D$. arnfieldi, $74.3 \%$ for $T$. axei, $6.4 \%$ for strongyles excluding $T$. axei, $S$. westeri and $P$. equorum, and $0 \%$ for eggs of anoplocephalidae and $E$. leuckarti. Prevalence in the Mongolian domestic horse was $72.4 \%$ for $D$. arnfieldi, $86.2 \%$ for $T$. axei, $51.8 \%$ for strongyles excluding $T$. axei, $0 \%$ for $S$. westeri and $P$. equorum, $3.4 \%$ for eggs of anoplocephalidae, and $6.8 \%$ for E. leuckarti.

The prevalence of parasite infection in each herd was high, with $87.5 \%$ for Przewalski's horse herds, 90.3\% for Asiatic wild ass herds, and 100\% for Mongolian domestic horse herds. Means, bootstrap confidence intervals, and medians for the prevalences are listed in Table 1.

Comparing strongyles, including $T$. axei, between the three species, we found a highly significant difference (ANOVA, $p=0.004$ ): Asiatic wild ass had the highest parasitic burden of strongyles, including $T$. axei (mean= 814.87 eggs in $10 \mathrm{~g}$ of feces with CSFM), followed by domestic horses (mean=674.03 eggs in $10 \mathrm{~g}$ of feces with CSFM), while Przewalski's horses had the lowest load (mean=198.52 eggs in $10 \mathrm{~g}$ feces with CSFM) (Fig.1). Comparing only the two wild equid species, the significant difference in strongyles, including $T$. axei, burden was even higher (ANOVA, $p \leq 2 \mathrm{e}-16$ ).

When testing the differences in burden based on individual parasite species among the three equid species, only the difference in parasite load of $D$. arnfieldi L1 larvae and eggs was significant (ANOVA, $p \leq 0.0021$ ). Again, Asiatic wild ass had the highest burden, followed by the domestic horse and the Przewalski's horse. When comparing the number of eggs of $T$. axei between Asiatic wild ass and Przewalski's horses, the Asiatic wild asses had a significantly higher burden (ANOVA, $p=<0.036$ ).

Gasterophilus spp. larvae were found in some fecal samples of all three equid species, as well as in the stomach of a Przewalski's horse euthanized subsequent to a trauma. 


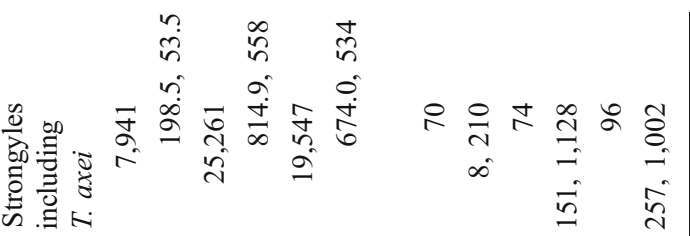

$\frac{\sqrt[3]{2}}{\sqrt[3]{2}}$

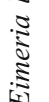

○ 0 ○

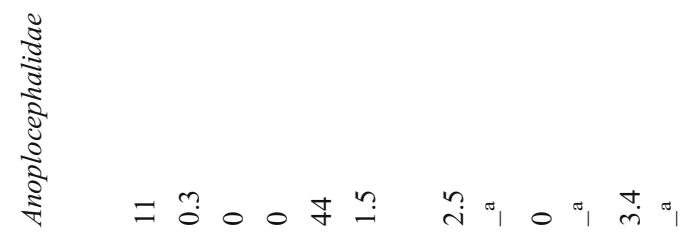

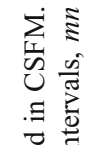

뇐

$9007 \pi$
4

है

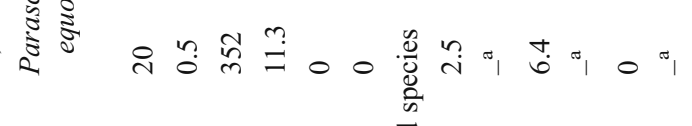

焉

ग)

के

है

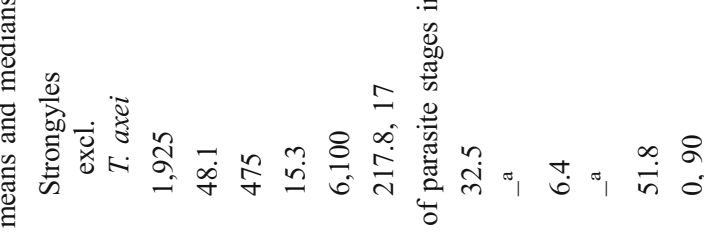

离

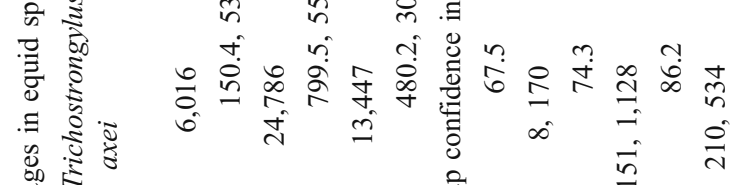

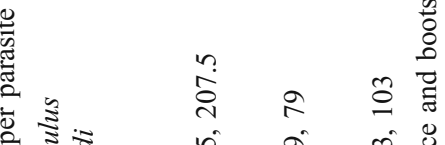

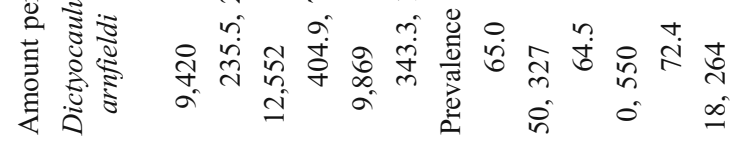




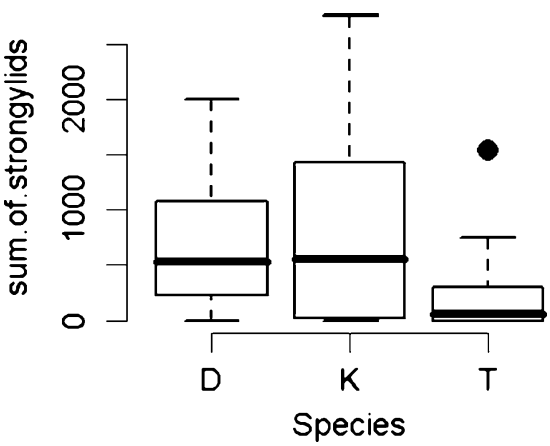

Fig. 1 Strongyles including T. Axei counts of individuals from one species compared between the three equid species. Domestic horses, Asiatic wild asses, Przewalski's horses in the Gobi Desert ecosystem. Presented as a grouped sample for every equid species. Semiquantitative egg count with CSFM. Horizontal axis equid species, $D$ domestic horses, $K$ Khulan, Asiatic wild ass, $T$ Takhi, Przewalski's horse. Vertical axis strongyles including T. axei, from every equid species. Asiatic wild ass, mean $=814.87$ eggs in $10 \mathrm{~g}$ with CSFM. Domestic horses, mean $=674.03$ eggs in $10 \mathrm{~g}$ feces with CSFM. Przewalski's horses, mean $=198.52$ eggs in $10 \mathrm{~g}$ feces with CSFM

\section{Discussion}

The present work evaluated the parasitic burden and parasite diversity of three sympatric living equids in the Great Gobi part "B" in Mongolia. In this park, Przewalski's horses live together, completely free ranging, with Asiatic wild asses and Mongolian domestic horses. Qualitative and semi-quantitative analyses of fecal samples were performed with CSFM. Elias et al. (2002) previously suggested that the determination of parasite prevalence within a herd is more sensitive when using CSFM, compared to McMaster. Due to the extreme field conditions, larval cultures were not performed. Since the samples were only collected in summer, we could not test for a seasonal influence on the results.

D. arnfieldi, T. axei, strongyles, S. westeri, eggs of anoplocephalidae, $P$. equorum, E. leuckarti, and occasionally Gasterophilus spp. larvae were detected in the fresh feces. Individual parasite burden, as well as the sum of similar acting parasites and parasite prevalence within a herd, were compared with previous studies to see if any associations could be found. Strongyles, excluding T. axei, had prevalences of $32.5 \%$ in Przewalski's horses, $6.4 \%$ in Asiatic wild asses, and $51.8 \%$ in Mongolian domestic horses. This is lower than prevalences previously reported of $75.9 \%, 96.2 \%$, and $98.7 \%$, respectively (Elias et al. 2002). Previously, prevalences between 80 and $100 \%$ for small strongylids and $17-100 \%$ for large strongylids had been recorded (Beelitz et al. 1996; Ogbourne 1976; Reinemeyer et al. 1984). The lower prevalences in this study may be explained by the short sampling period of only 2 months.
Eggs of anoplocephalidae showed a prevalence of $2.5 \%$ for Przewalski's horses, $0 \%$ for Asiatic wild asses, and 3.4\% for Mongolian domestic horses during our sampling period. These values are lower than those found in wild equids by Elias et al. (2002)), with prevalences of $6.1 \%$ and $1.9 \%$, respectively, and higher than their reported prevalence of $1.3 \%$ for domestic horses. Tapeworms seem to be shed at a maximum in spring (Elias et al. 2002), which was not the sampling period in this study. Furthermore, tapeworms have a lower prevalence in equids that are not dewormed due to higher competition with other parasites (Elias et al. 2002). Coproscopic examinations are not the method of choice to determine an anoplocephalid infection, since eggs are shed by the host only sporadically (Elias et al. 2002).

Prevalences for $P$. equorum in our study were: Przewalski's horses $2.5 \%$, Asiatic wild asses $6.4 \%$, and $0 \%$ in Mongolian domestic horses. The literature suggests prevalences between 3-18\% (Elias et al. 2002). Adult equids establish a protective immunity against ascarids, and positive samples could only be found in groups with foals. Similar to a previous study, Asiatic wild asses in this study do not appear to have protection against ascarids as adults (Elias et al. 2002). In $6.4 \%$ of our Mongolian domestic horse samples, E. leuckarti was found. Previously, Elias et al. (2002) found E. leuckarti in only one Przewalski's horse. Coccidiosis in domestic equids is rare with a prevalence of about 1\% (Bauer and Bürger 1984). Furthermore, the egesting rate seems to be low and therefore not easily detectable (Bauer and Bürger 1984).

In this study, of all the parasites, T. axei had the highest prevalences with $67.5 \%$ in Przewalski's horses, $74.3 \%$ in Asiatic wild asses, and $86.2 \%$ in Mongolian domestic horses. No trichostrongylids were found in the previous study by Elias et al. (2002). At that time, Przewalski's horses and ruminants were not grazing on the same pastures. Cross-infection between ruminants and equids must have occurred at a later time when, after the Przewalski's horse range expansion, their respective habitat overlapped. $T$. axei, primarily a ruminant abomasal parasite (Schnieder et al. 2006; Elias et al. 2002), only occurs in equid species grazing on the same pastures as ruminants (Eysker et al. 1986). The most common wild ruminant in the Great Gobi "B" is the black-tailed gazelle. Domestic ruminants are the cashmere goat, sheep, and cattle. Herders graze them close to the park border, and they are tolerated by the authorities in the park's buffer zone during very harsh periods in winter and spring.

D. arnfieldi showed prevalences of $65.0 \%$ in Przewalski's horses, $64.5 \%$ in Asiatic wild asses, and $72.4 \%$ in Mongolian domestic horses in our study. This is a slightly higher occurrence than expected (Lyons et al. 1985; Pandey 1980). In the previous study, no infection with lungworms 
(D. arnfieldi) was found (Elias et al. 2002). At that time, only one harem group of Przewalski's horses was living in the wild, with a small home range. Presumably, there was not much overlap between home ranges of Asiatic wild asses, Przewalski's horses, and domestic horses. Our study reports for the first time lungworm infections in free-ranging Przewalski's horses. Donkeys are the major host and most important reservoir for equid lungworms. They are considered to act as the source of infection; horses play only an ancillary role and become infected after pastured with donkeys (Schnieder et al. 2006; George et al. 1981; Beelitz et al. 1996; Mehlhorn et al. 1993; Morris et al. 2004). As expected from the literature, lungworm infection in this examination shows that Asiatic wild asses have a significantly higher load of lungworms than Przewalski's horses. The Przewalski's horses may have only become infected with lungworms after years of overlapping home ranges with Asiatic wild asses. Patent infections usually only occur in donkeys, mules, and asses, whereas in horses, larval development is often arrested in the fifth stage. Large numbers of parasites can accumulate in the lungs of asses without clinical disease. A horse-to-horse transmission has been reported, where $D$. arnfieldi caused non-patent infections with signs of coughing, increased respiratory rate, and nasal discharge (Boyle and Houston 2006). We found these signs in Mongolian domestic horses; however, they were absent in their wild counterparts. Coevolution of the parasites and the wild equids in the Gobi have possibly engendered immunologic advantages.

Age differences were highly significant in Przewalski's horses and domestic horses. Some parasites like $S$. westeri, E. leuckarti, and P. equorum are more commonly seen in foals and younger individuals as immunity provides sufficient protection as they age, whereas other parasites, like eggs of anoplocephalidae., strongyles, $T$. axei and $D$. arnfieldi, are commonly seen in individuals of all ages because protective immunity is insufficient (Schnieder et al. 2006; Wakelin 1996; Beelitz et al. 1996; Bauer and Bürger 1984). As described in the literature (Schnieder et al. 2006; Elias et al. 2002), we found that $S$. westeri was significantly more often present in younger individuals; P. equorum also showed this age difference, though it was not significant. However, E. leuckarti showed no significant difference between older or younger individuals, possibly due to the low sample size. D. arnfieldi, T. axei, strongyles, and eggs of anoplocephalidae showed higher or equally high burden in adult equids, as predicted by the literature. Though not statistically significant, young horses, aged up to 1 year, showed slightly higher variability in parasites, with similar quantitative levels as adult horses (Schnieder et al. 2006; Elias et al. 2002). This higher variability may be due to the young host's immune system establishing a protective immunity to some parasites, thus decreasing the parasite variability with age (Schnieder et al. 2006). In Przewalski's horses, the effect of immunity depression during pregnancy (Wakelin 1996) is thought to be greatly reduced due to the nonexistence of a peripaturient rise in parasite infections in Przewalski's horses (Elias et al. 2002).

The sum of strongyles, including $T$. axei, compared between the species was highly significant with Asiatic wild ass having the highest parasitic burden, followed by domestic horses, and then the Przewalski's horses, which had a much lower burden (Fig. 1). Comparing only the two wild equid species, Przewalski's horse and Asiatic wild ass, the significant difference in their strongyles, including T. axei, the burden was even higher. This trend could also be seen for the majority of parasites $(D$. arnfieldi, T. axei, S. westeri, P. equorum) evaluated in this study. These data can be analyzed in view of a study by Kaczensky et al. (2008) concerning resource selection by sympatric wild equids in the Mongolian Gobi. Between November 2001 and May 2004, Kaczensky et al. (2008) studied nine satellite radio-collared Przewalski's horses and seven Asiatic wild asses to investigate resource selection in these sympatric wild equids. Their results showed (inter alia) sympatric Asiatic wild asses and Przewalski's horses select different plant communities for grazing. Asiatic wild asses have 10 times larger home ranges than Przewalski's horses, and they have a completely different social structure. Kaczensky et al. (2008) concluded that these two sympatric wild equids are not in direct competition. The home range of Przewalski's horses is $471 \mathrm{~km}^{2}$ (range: $152-826 \mathrm{~km}^{2}$ ) and $5860 \mathrm{~km}^{2}$ (range: 4,449$7,186 \mathrm{~km}^{2}$ ) for Asiatic wild asses (Kaczensky et al. 2008). Przewalski's horses live in stable harem groups (average 5.6 adult mares and 11.1 offspring) with one dominant stallion, or in bachelor groups with varying stability. Asiatic wild asses are often sighted in groups of hundreds of individuals, characterized by loose associations and single individuals (Kaczensky et al. 2008; Feh 2002). Kaczensky et al. (2008) suggested that Asiatic wild asses in the Gobi are likely to be organized in fission-fusion groups (mean group size 28.4 animals; range: 1-1,000 animals), which has previously been described for other equids in arid environments (Sundaresan et al. 2006). The social structure of fission-fusion groups in Asiatic wild asses allows far more individuals to live temporarily at high concentrations in the same area. Sometimes unstructured groups of 500-1,000+ animals were observed. This limited space increases the potential environmental infectious doses (Ortiz et al. 2006). Being nomadic animals, they do not remain in one location for a long period of time; however, most parasites do not need a long external maturation phase in order to be infectious, therefore, reinfection may occur quite often. 


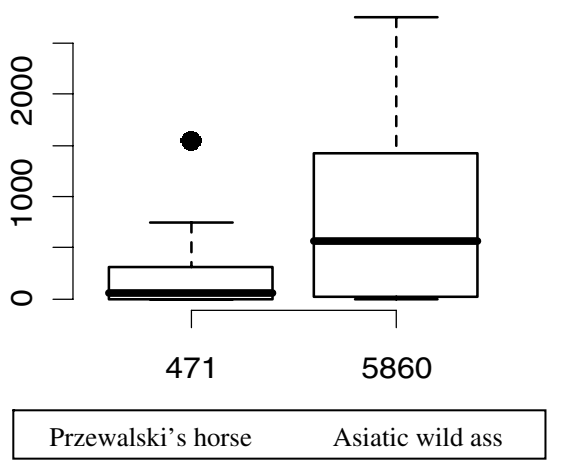

Fig. 2 The mean home range size of the two wild equid species compared to their mean parasite burden of strongyles including $T$. axei Przewalski's horse and Asiatic wild ass in relation to their mean sum of strongyles including $T$. axei burden of individuals from each species in the Gobi Desert ecosystem. Horizontal axis mean home range size of Przewalski's horses, mean $=471 \mathrm{~km}^{2}$; mean home range size of Asiatic wild asses, mean $=5860 \mathrm{~km}^{2}$. Vertical axis strongyles including T. axei egg count with CSFM per individual per $10 \mathrm{~g}$ of feces. Asiatic wild ass, mean $=814.87$ eggs in $10 \mathrm{~g}$ with CSFM; Przewalski's horses, mean $=198.52$ eggs in $10 \mathrm{~g}$ feces with CSFM

Przewalski's horse, socially structured in small, stable harem groups or in bachelor groups, have far smaller home ranges and therefore have a significantly lower exposure to contaminated patches (Fig. 2). Mongolian domestic horses stay in groups of 10-50 horses. Herders move them from one green pasture to another, without paying attention to which horses were grazing and defecating there before. Furthermore, these domestic equids could differ immunologically with respect to parasites from their wild counterparts, are handled occasionally by herders, and may suffer more from stress (Elias et al. 2002; Sharkhuu et al. 2000).

\section{Conclusion}

Despite the sometimes quite high egg- and larval output, Przewalski's horses and Asiatic wild asses appear to cope well with their respective parasitic load and parasites appear to be, at the most, a minor pathogen for them. In comparison, domestic horses obviously have problems with parasitic infections, as manifested by diarrhea, loss of weight, coughing, and scrubby fur. The risk of cross-infection can be high between the sympatric equids (Fig. 3), but also between ruminants and equids living in the Gobi "B". It is interesting to note that the Przewalski's horse, after many generations in captivity, appears to have retained this wild equid advantage vis-ávis gastrointestinal parasite infection.

There are few investigations concerning the infestation status of parasites in wild equids, particularly in the Asiatic wild ass and Przewalski's horse. These results may help further management of both wild and captive populations. More detailed information regarding interactions between the three species and possible effects of these interactions on parasite burden would be an interesting topic for future research. This study highlights the importance of variables such as home range-size, resource selection, and social systems that may impact the immunity of sympatric hosts to parasites.

Acknowledgements This research was conducted within the framework of the Przewalksi's horse reintroduction project of the International Takhi Group (ITG). Funding was provided by the Austrian Science Fund (FWF, projects P14992 \& P18624). Thank you very much to R. Drury, A. Joachim, N. Enkhsaikhaan, Aagi, T. Ruf, A. Zedrosser, F. Tiedeman, V. Sahlén, the ITG staff, the local rangers and their families, as well as everyone who was somehow involved in the project for their exceedingly great support.
Fig. 3 The risk of cross-infection between the sympatric equids. Przewalski's horse herd with one single Asiatic wild ass on the right

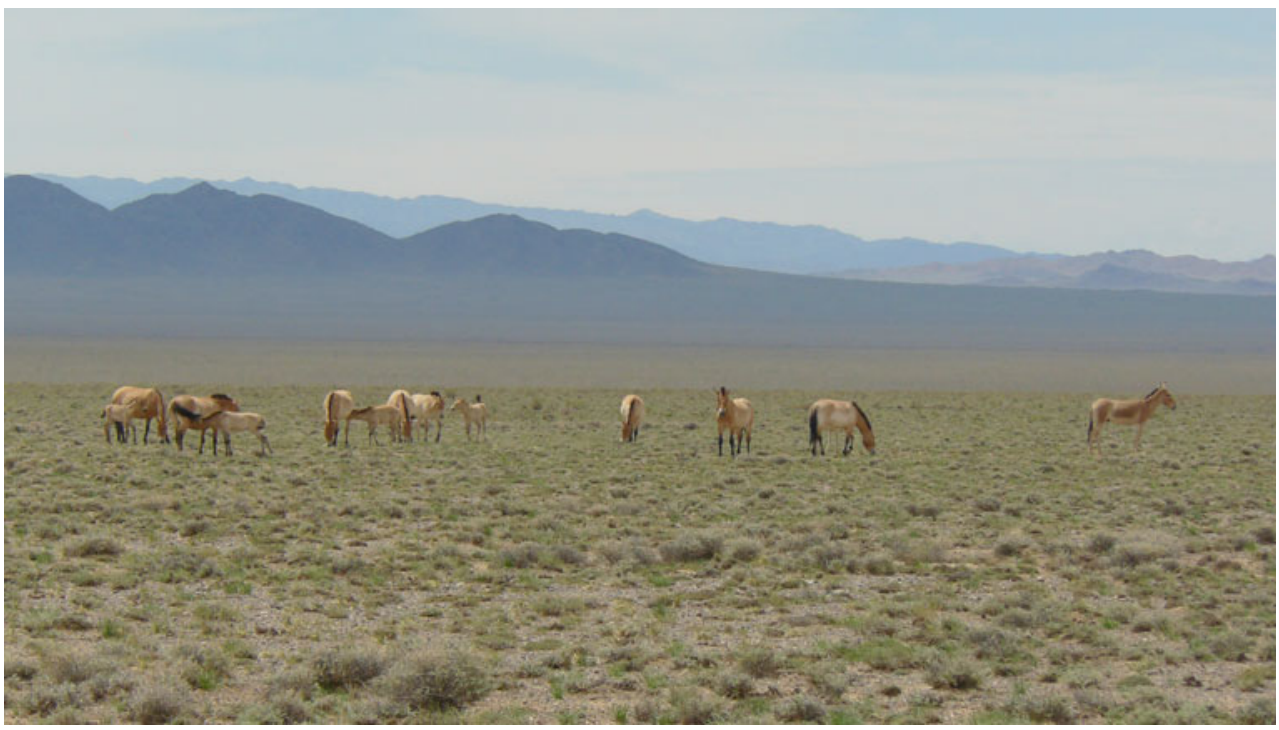


Open Access This article is distributed under the terms of the Creative Commons Attribution Noncommercial License which permits any noncommercial use, distribution, and reproduction in any medium, provided the original author(s) and source are credited.

\section{References}

Bauer C, Bürger H-J (1984) Zur Biologie von Eimeria leuckarti (Flesch, 1883) der Equiden. Berl Münch Tieärztl Wschr 97:367372 (in German)

Beelitz P, Göbel E, Gothe R (1996) Endoparasites of donkeys and horses kept in companionship in Upper Bavaria: species spectrum and incidence. Tierärztl Prax 24:471-475

Boyd L, Houpt KA (1994) Przewalski's Horse. State University of New York Press, Albany, The history and biology of an endangered species. Suny series in endangered animals

Boyle AG, Houston R (2006) Parasitic pneumonitis and treatment in horses. Clin Tech Eq Pract 5:225-232

Crawley MJ (2007) The R-book. John Wiley \& Sons Ltd., England

Elias F, Sterregaard F, Baumgartner R, Walzer C, Slotta-Bachmayr L, Ganbataar O, Bajalagmaa N, Isenbügel E, Deplazes P (2002) Parasitologic examinations in reintroduced Przewalski horses (Equus c. przewalskii) compared to mongolian domestic horses (E. caballus) and Dschiggetais (E. h. hemionus) in the Dzungarian Gobi, Mongolia. Pro. EAZWV \& EWDA May 8-12. Heidelberg, Germany, pp 233-240

Eysker M, Jansen J, Mirck MH (1986) Control of strongylosis in horses by alternate grazing of horses and sheep and some other aspects of the epidemiology of strongylide infections. Vet Parasitol 19:103-115

Feh C (2002) Relationships and communication in socially natural horse herds. Dorothy Russell Havemeyer Foundation Workshop, 13-16 June, 2002. Holar, Iceland

Fernandez-Gimenez ME, Allen-Diaz B (1999) Testing a nonequilibrium model of rangeland vegetation dynamics in Mongolia. J Appl Ecol 36:871-855

George LW, Tanner ML, Roberson EL, Burke TM (1981) Chronic respiratory disease in a horse infected with Dictyocaulus arnfieldi. J Am Vet Med Assoc 179:820-822

Hoby S, Schwarzenberger F, Doherr MG, Robert N, Walzer C (2006) Steroid hormone related male biased parasitism in chamois, Rupicapra rupicapra rupicapra. Vet Parasitol 138:337-348

International Union for the Conservation of Nature and Natural Resources, Species Survival Commission Re-Introduction Specialist Group (1998) IUCN/SSC guidelines for re-introduction. IUCN/SSC, Gland, Switzerland

International Union for the Conservation of Nature and Natural Resources (2006) Red List of threatened Species. IUCN, Gland, Switzerland

Kaczensky P, Walzer C, Steinhauer-Burkart B (2005) Great Gobi B Strictly Protected Area. ECO Nature Edition. Nature-Guide No.3. Steinhauer-Burkart OHG

Kaczensky P, Sheehy DP, Johnson DE, Walzer C, Lkhagvasuren D, Sheehy CM (2006) Room to Roam? The Threat to Khulan (Wild Ass) from Human Intrusion. Mongolia Discussion Papers. East Asia and Pacific Environment and Social Development Department. World Bank, Washington, DC
Kaczensky P, Enkhsaihan N, Ganbaatar O, Walzer C (2007) Identification of herder-wild equid conflicts in the Great Gobi B Strictly Protected Area in SW Mongolia. Exploration into the Biological Resources of Mongolia 10:99-116

Kaczensky P, Walzer C (2008) Der Asiatische Wildesel - bedrohter Überlebenskünstler in der Wüste Gobi. Z KoÉln Zoo 51:147-163 (in German)

Kaczensky P, Ganbaatar O, von Wehrden H, Walzer C (2008) Resource selection by sympatric wild equids in the Mongolian Gobi. J Appl Ecol 45:1762-1769

Kuehn R, Kaczensky P, Lkhagvasuren D, Pietsch S, Walzer C (2006) Differentiation of meat samples from domestic horses (Equus caballus) and asiatic wild asses (Equus hemionus) using a species-specific restriction site in the mitochondrial cytochrome $\mathrm{b}$ region. Mongol J Biol Sci 4(2):57-62

Lyons ET, Tolliver SC, Drudge JH, Swerczek TW, Crowe MW (1985) Lungworms (Dictyocaulus arnfieldi): prevalence in live equids in Kentucky. Am J Vet Res 46:921-923

Mehlhorn H, Düwel D, Raether W (1993) Diagnose und Therapie der Parasitosen von Haus-, Nutz-, und Heimtieren, 2nd edn. Gustav Fischer, Stuttgart, New York

Morris C, Trawford A, Svendsen E (2004) Donkey: hero or villain of the parasite world? Past, present and future. Vet Parasitol 125:43-58

Mohr E, Volf J (1971) Das Urwildpferd. A.Ziemsen Verlag, Wittenberg Lutherstadt

Ogbourne CP (1976) The prevalence, relative abundance and site distribution of nematodes of the subfamily Cyathostominae in horses killed in Britain. J Helminthol 50:203-214

Ortiz J, Ruiz de Ybanez R, Abaigar T, Goyena M, Garijo M, Espeso G, Cano M (2006) Output of gastrointestinal nematode eggs in the feces of captive gazelles (Gazella dama mhorr, gazella cuvieri and Gazella dorcas neglecta) in a semiarid region of southeastern Spain. J Zoo Wildl Med 37:249-254

Pandey VS (1980) Epidemiological observations on lungworm, Dictyocaulus arnfieldi, in donkeys from Morocco. J Helminthol 54:275-279

R Development Core Team (2008) R: A language and environment for statistical computing. R Foundation for Statistical Computing, Vienna, Austria. ISBN 3-900051-07-0, URL http://www.Rproject.org.

Reinemeyer CR, Gabel AA, Herd RP (1984) The prevalence and intensity of internal parasites of horses in the USA. Vet Parasitol 15:75-83

Schnieder T. (ed.), Boch J, Supperer R (2006) Veterinärmedizinische Parasitologie. Parey MVS Medizinverlage Stuttgart, 6th ed.

Sharkhuu G, Ulanbayar O, Tuya Sh, Sunjidmaa D, Nyamosor P, Dolgorsuren B, Tungalag T (2000) Report on the study of helminth infections of Przewalski horses (Tachi) in Hustai (19942000). Mongolian Agriculture University, Ulaanbaatar

Sundaresan SR, Fischhoff IR, Dushoff J, Rubenstein DI (2006) Network metrics reveal differences in social organization between two fission-fusion species. Grevy's zebra and Onager Oecologia 151:140-149

Walzer C, Baumgartner R, Ganbataar O, Stauffer C (2004) Boxing a wild horse for Mongolia - Tips, Tricks and Treats. European Association of Zoo and Wildlife Veterinarians (EAZWV), 19-23. Mai, 2004. ed. Erken AHMDorrestein GM:153-157. Ebeltoft, Denmark

Wakelin D (ed) (1996) Immunity to parasites: how parasitic infections are controlled, 2nd edn. Cambridge University Press, Cambridge 